\title{
THE GARDEN SEAT
}

ITs former green is blue and thin, And its once firm legs sink in and in;

Soon it will break down unaware, Soon it will break down unaware.

At night when reddest flowers are black Those who once sat thereon come back; Quite a row of them sitting there, Quite a row of them sitting there.

With them the seat does not break down, Nor winter freeze them, nor floods drown, For they are as light as upper air, They are as light as upper air!

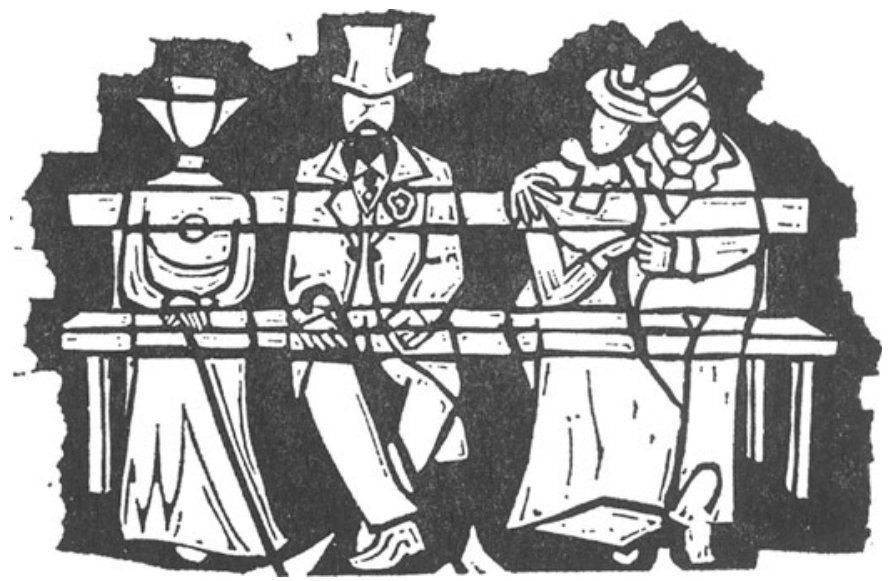

